\title{
FLOTAC: A promising technique for detecting helminth eggs in human faeces
}

\author{
Stefanie Knopp ${ }^{a, b, *}$, Dominik Glinz ${ }^{a, c}$, Laura Rinaldi ${ }^{d}$, \\ Khalfan A. Mohammed ${ }^{b}$, Eliézer K. N'Goran ${ }^{c, e}$, J. Russell Stothard ${ }^{f}$, \\ Hanspeter Marti ${ }^{g}$, Giuseppe Cringoli ${ }^{d}$, David Rollinson ${ }^{f}$, Jürg Utzinger ${ }^{a}$
}

\author{
a Department of Public Health and Epidemiology, Swiss Tropical Institute, P.O. Box, CH-4002 Basel, Switzerland \\ ${ }^{\mathrm{b}}$ Helminth Control Laboratory Unguja, Ministry of Health and Social Welfare, P.O. Box 236, Mianzini, Zanzibar, Tanzania \\ ' Centre Suisse de Recherches Scientifiques, 01 BP 1303, Abidjan 01, Côte d'Ivoire \\ 'Department of Pathology and Animal Health, CREMOPAR Regione Campania, University of Naples 'Federico II', \\ Via della Veterinaria 1, 80137 Naples, Italy \\ e UFR Biosciences, Université de Cocody-Abidjan, 22 BP 770, Abidjan 22, Côte d'Ivoire \\ ${ }^{f}$ Wolfson Wellcome Biomedical Laboratories, Biomedical Parasitology Division, Department of Zoology, \\ Natural History Museum, Cromwell Road, London SW7 5BD, UK \\ g Department of Medical and Diagnostic Services, Swiss Tropical Institute, P.O. Box, CH-4002 Basel, Switzerland
}

Received 19 February 2009; received in revised form 7 May 2009; accepted 7 May 2009

Available online 1 July 2009

\author{
KEYWORDS \\ Ascaris lumbricoides; \\ Hookworm; \\ Trichuris trichiura; \\ Diagnosis; \\ FLOTAC; \\ Kato-Katz
}

\begin{abstract}
Summary There is a tendency to neglect diagnostic issues in the era of 'preventive chemotherapy' in human helminthiases. However, accurate diagnosis cannot be overemphasized for adequate patient management and monitoring of community-based control programmes. Implicit is a diagnostic dilemma: the more effective interventions are in reducing helminth egg excretion, the less sensitive direct parasitological tests become. Here, experiences gained thus far with the FLOTAC technique for diagnosing common soil-transmitted helminth infections are summarized. A single FLOTAC has higher sensitivity than multiple Kato-Katz thick smears in detecting low-intensity infections. Further validation of the FLOTAC technique in different epidemiological settings is warranted, including diagnosis of intestinal schistosomiasis and food-borne trematodiases.

(c) 2009 Royal Society of Tropical Medicine and Hygiene. Published by Elsevier Ltd. All rights reserved.
\end{abstract}

\section{Introduction}

Based on a presentation to the Royal Society of Tropical Medicine \& Hygiene Research in Progress meeting on 18 December 2008. This oral presentation was awarded second prize at the meeting.

* Corresponding author. Tel.: +41 612848226 fax: +41 612848105 .

E-mail address: s.knopp@unibas.ch (S. Knopp).
The key strategy for reducing the morbidity caused by soil-transmitted helminth infections (Ascaris lumbricoides, hookworm and Trichuris trichiura) in endemic countries is large-scale administration of anthelminthic drugs to

0035-9203/\$ - see front matter @ 2009 Royal Society of Tropical Medicine and Hygiene. Published by Elsevier Ltd. All rights reserved. doi:10.1016/j.trstmh.2009.05.012 
Table 1 Arithmetic mean eggs per gram (EPG), prevalence and sensitivity (including 95\% confidence interval (CI)) of a single FLOTAC and multiple Kato-Katz thick smears, as determined in cross-sectional studies with schoolchildren from Côte d'Ivoire and Zanzibar. Combined results from FLOTAC and multiple Kato-Katz thick smears were considered diagnostic 'gold' standard, thereby setting the sensitivity at $100 \%$.

\begin{tabular}{|c|c|c|c|c|c|c|c|c|c|c|c|c|}
\hline \multirow{2}{*}{$\begin{array}{l}\text { Setting, } \\
\text { year }\end{array}$} & \multirow{2}{*}{$\begin{array}{l}\text { Population } \\
\text { sample (age) }\end{array}$} & \multirow[t]{2}{*}{ Parasite } & \multicolumn{2}{|c|}{ Diagnostic 'gold' standard } & \multicolumn{4}{|l|}{ FLOTAC } & \multicolumn{3}{|c|}{ Kato-Katz } & \multirow[t]{2}{*}{ Reference } \\
\hline & & & $\begin{array}{l}\text { Method } \\
\text { and } \\
\text { sampling } \\
\text { effort }\end{array}$ & $\begin{array}{l}\text { Preva- } \\
\text { lence } \\
(\%)\end{array}$ & $\begin{array}{l}\text { Duration of } \\
\text { stool } \\
\text { preservation } \\
\text { in SAFa }\end{array}$ & $\begin{array}{l}\text { Arith- } \\
\text { metic } \\
\text { mean } \\
\text { EPG }\end{array}$ & $\begin{array}{l}\text { Preva- } \\
\text { lence } \\
(\%)\end{array}$ & $\begin{array}{l}\text { Sensitivity (\%) } \\
{[95 \% \mathrm{CI}]}\end{array}$ & $\begin{array}{l}\text { Arith- } \\
\text { metic } \\
\text { mean } \\
\text { EPG }\end{array}$ & $\begin{array}{l}\text { Preva- } \\
\text { lence } \\
(\%)\end{array}$ & $\begin{array}{l}\text { Sensitivity (\%) } \\
{[95 \% \mathrm{Cl}]}\end{array}$ & \\
\hline $\begin{array}{l}\text { Côte } \\
\text { d'Ivoire, } \\
2006\end{array}$ & $\begin{array}{l}102 \\
\text { schoolchildren } \\
\text { (6-14 years) }\end{array}$ & Hookworm & $\begin{array}{l}1 \text { FLOTAC plus } \\
2 \text { Kato-Katz } \\
\text { (1 faecal } \\
\text { sample) }\end{array}$ & 74.5 & $\sim 6$ months & 37.7 & 65.7 & $\begin{array}{l}88.2 \\
{[78.2-94.1]}\end{array}$ & 155.8 & 51.0 & $\begin{array}{l}68.4 \\
{[56.6-78.3]}\end{array}$ & $\begin{array}{l}\text { Utzinger } \\
\text { et al. }{ }^{6}\end{array}$ \\
\hline \multirow[t]{3}{*}{$\begin{array}{l}\text { Zanzibar, } \\
2007\end{array}$} & $\begin{array}{l}279 \\
\text { schoolchildren } \\
\text { (7-20 years) }\end{array}$ & T. trichiura & $\begin{array}{l}1 \text { FLOTAC plus } \\
3 \text { Kato-Katz } \\
\text { ( } 3 \text { faecal } \\
\text { samples) }\end{array}$ & 63.4 & $\sim 6$ months & 24.2 & 56.3 & $\begin{array}{l}88.7 \\
{[82.9-92.8]}\end{array}$ & 51.0 & 45.5 & $\begin{array}{l}71.8 \\
{[64.4-78.1]}\end{array}$ & $\begin{array}{l}\text { Knopp et } \\
\text { al. }^{5}\end{array}$ \\
\hline & & Hookworm & $\begin{array}{l}1 \text { FLOTAC plus } \\
3 \text { Kato-Katz } \\
\text { ( } 3 \text { faecal } \\
\text { samples) }\end{array}$ & 35.8 & $\sim 6$ months & 1.9 & 29.8 & $\begin{array}{l}83.0 \\
{[73.9-89.5]}\end{array}$ & 12.2 & 16.5 & $\begin{array}{l}46.0 \\
{[36.1-56.2]}\end{array}$ & $\begin{array}{l}\text { Knopp et } \\
\text { al. }^{5}\end{array}$ \\
\hline & & A. lumbricoides & $\begin{array}{l}1 \text { FLOTAC plus } \\
3 \text { Kato-Katz } \\
\text { (3 faecal } \\
\text { samples) }\end{array}$ & 22.9 & $\sim 6$ months & 52.2 & 19.0 & $\begin{array}{l}82.8 \\
{[70.9-90.7]}\end{array}$ & 278.2 & 16.1 & $\begin{array}{l}70.3 \\
{[57.4-80.8]}\end{array}$ & $\begin{array}{l}\text { Knopp et } \\
\text { al. }^{5}\end{array}$ \\
\hline \multirow[t]{3}{*}{$\begin{array}{l}\text { Côte } \\
\text { d'Ivoire, } \\
2008\end{array}$} & $\begin{array}{l}112 \\
\text { schoolchildren } \\
\text { (6-15 years) }\end{array}$ & Hookworm & $\begin{array}{l}1 \text { FLOTAC } \\
\text { (day 10) plus } \\
3 \text { Kato-Katz } \\
\text { (1 faecal } \\
\text { sample) }\end{array}$ & 38.4 & 10 days & 8.5 & 31.3 & $\begin{array}{l}81.4 \\
{[71.2-88.6]}\end{array}$ & 41.4 & 21.4 & $\begin{array}{l}55.8 \\
{[46.6-65.0]}\end{array}$ & $\begin{array}{l}\text { D. Glinz et } \\
\text { al., } \\
\text { unpublished }\end{array}$ \\
\hline & & Hookworm & $\begin{array}{l}1 \text { FLOTAC } \\
\text { (day 30) plus } \\
3 \text { Kato-Katz } \\
\text { (1 faecal } \\
\text { sample) }\end{array}$ & 36.6 & 30 days & 2.0 & 25.9 & $\begin{array}{l}70.7 \\
{[62.3-79.2]}\end{array}$ & 41.4 & 21.4 & $\begin{array}{l}58.5 \\
{[49.4-67.7]}\end{array}$ & $\begin{array}{l}\text { D. Glinz et } \\
\text { al., } \\
\text { unpublished }\end{array}$ \\
\hline & & Hookworm & $\begin{array}{l}1 \text { FLOTAC } \\
\text { (day 83) plus } \\
3 \text { Kato-Katz }\end{array}$ & 28.6 & 83 days & 1.8 & 17.0 & $\begin{array}{l}59.4 \\
{[50.3-68.5]}\end{array}$ & 41.4 & 21.4 & $\begin{array}{l}75.0 \\
{[67.0-83.0]}\end{array}$ & $\begin{array}{l}\text { D. Glinz et } \\
\text { al., } \\
\text { unpublished }\end{array}$ \\
\hline
\end{tabular}


Table 1 (Continued)

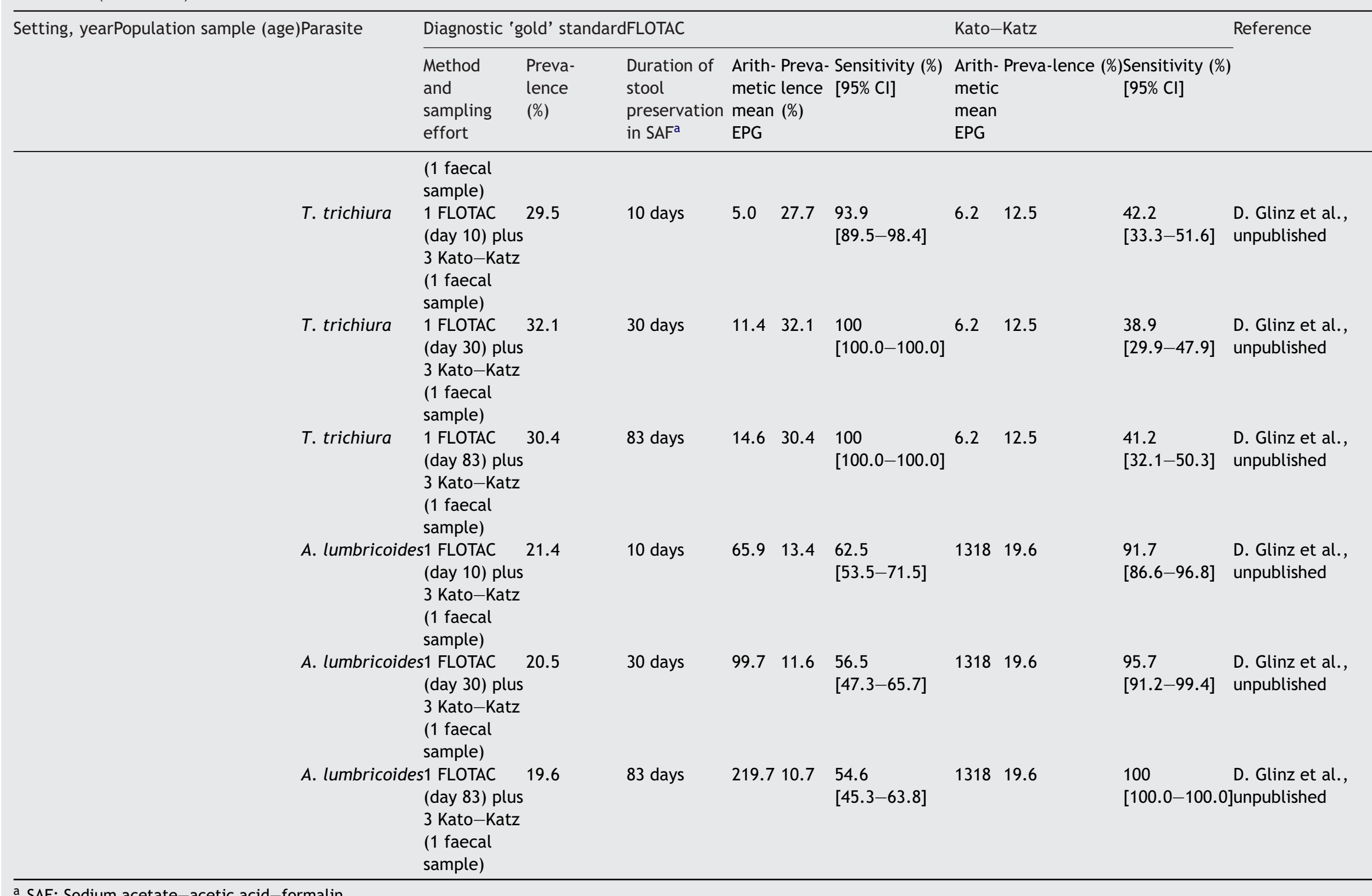

a SAF: Sodium acetate-acetic acid-formalin. 
high-risk groups, usually without prior diagnosis. This strategy is termed 'preventive chemotherapy'. 1 As a result of successful helminth control programmes, infection prevalences and intensities diminish, and hence direct diagnostic techniques become less sensitive. ${ }^{2}$ Here, we summarize our experiences gained thus far with a new faecal egg-count method-the FLOTAC technique ${ }^{3}$-for diagnosis of human helminth infections. Comparison is made between a single FLOTAC and multiple Kato-Katz thick smears. ${ }^{4}$

\section{Methods}

So far, we have been involved in three studies using FLOTAC for human helminth diagnosis: one in $Z^{2}$ anzibar ${ }^{5}$ and two in Côte d'Ivoire ${ }^{6}$ (D. Glinz et al., unpublished). The studies followed cross-sectional epidemiological designs and a total of 493 schoolchildren was enrolled. In both Côte d'Ivoire studies a single faecal sample was collected per child, and two to three Kato-Katz thick smears were prepared using $41.7 \mathrm{mg}$ templates. In Zanzibar, three consecutive faecal samples were collected and one Kato-Katz thick smear examined per sample. Additionally, $\sim 1 \mathrm{~g}$ of stool from each child was preserved in sodium acetate-acetic acid-formalin (SAF) and subjected to the FLOTAC technique. Preserved stool samples from the first Côte d'Ivoire study and from Zanzibar were transferred to Naples, Italy, and processed $\sim 6$ months after stool collection. Samples from the second Côte d'Ivoire study were examined on the spot, 10, 30 and 83 days after collection.

Detailed procedures of FLOTAC have been described elsewhere. ${ }^{3,5,6}$ In brief, in the first Côte d'Ivoire and the Zanzibar study, flotation solutions no. 4 (FS4; sodium nitrate, specific gravity=1.20) and 13 (FS13; zinc sulphate plus potassium iodomercurate, specific gravity $=1.45$ ) were used. In the second Côte d'Ivoire study an additional washing step with ether was performed to facilitate a clearer reading under the microscope. Here, FS4 and FS7 (zinc sulphate, specific gravity $=1.35$ ) were employed. Eggs per gram of stool (EPG) for each helminth species were calculated. Combined results (single FLOTAC plus multiple Kato-Katz) were considered diagnostic 'gold' standard.

\section{Results}

Key results from the three studies are summarized in Table 1. The first Côte d'Ivoire study showed that a single FLOTAC is more sensitive than duplicate Kato-Katz for hookworm diagnosis (sensitivity: 88.2 vs. $68.4 \%$ ). These findings were confirmed in Zanzibar: the sensitivity of a single FLOTAC for hookworm diagnosis was $83.0 \%$, whereas triplicate Kato-Katz had a sensitivity of only $46.0 \%$. Importantly, FLOTAC was also more sensitive for the diagnosis of $T$. trichiura and $A$. lumbricoides. In the second Côte d'Ivoire study, FLOTAC had a higher sensitivity than triplicate Kato-Katz for $T$. trichiura diagnosis at each time point and for hookworm diagnosis at days 10 and 30 poststool conservation, but not at day 83. In this study, FLOTAC was consistently less sensitive than triplicate Kato-Katz for diagnosis of $A$. lumbricoides. Whereas an apparent decline in sensitivity of FLOTAC was observed for hookworm and
A. lumbricoides diagnosis as a function of stool preservation duration, the sensitivity for $T$. trichiura diagnosis increased from 93.9 to $100 \%$.

\section{Discussion}

Our experiences to date are that a single FLOTAC is more sensitive than multiple Kato-Katz thick smears for diagnosing low-intensity soil-transmitted helminth infections. Idiosyncrasies of the epidemiological settings might explain some of the discrepancies in diagnostic sensitivity. Moreover, the additional washing step with ether in the second Côte d'Ivoire study warrants further consideration. As expected, Kato-Katz performs well when EPGs are reasonably high. For example, the sensitivity of Kato-Katz in the second Côte d'Ivoire study was higher than FLOTAC for $A$. lumbricoides diagnosis, but lower for $T$. trichiura. In this setting, $A$. lumbricoides infections were comparatively high (mean intensity: 1318 EPG according to triplicate Kato-Katz), but $T$. trichiura infections were of low intensity (6.2 EPG using triplicate Kato-Katz). In Zanzibar, where EPGs of all soil-transmitted helminth infections were low, FLOTAC had a consistently higher sensitivity than multiple Kato-Katz.

The apparent decrease in sensitivity of FLOTAC observed as a function of longer stool preservation duration in the second Côte d'Ivoire study, particularly for hookworm diagnosis, seems-at first sight-surprising. Indeed, the first Côte d'Ivoire and the Zanzibar study with faecal samples preserved in SAF for $\sim 6$ months revealed high sensitivities for hookworm diagnosis. However, in a separate calibration of FLOTAC with samples also stored in SAF for $\sim 6$ months and using different flotation solutions and washing steps with and without ether, it could be shown that hookworm eggs were well detected but only in the absence of ether. Hence, the apparent decline in the sensitivity for hookworm diagnosis with FLOTAC seems not to be a methodological issue with FLOTAC. Instead, we speculate that hookworm eggs are destroyed by SAF preservation and the concurrent use of ether. An important lesson learned is that helminth-specific eggs must be considered independently when using the FLOTAC technique with respect to: (1) the floatation solution; (2) the use of ether; and (3) the medium used for faecal preservation (e.g. SAF or formaldehyde). What is known for one parasite cannot be readily transferred to other parasites.

Advantages and disadvantages of the FLOTAC and Kato-Katz techniques are summarized in Supplementary Table 1. Although FLOTAC is highly sensitive for low-intensity soil-transmitted helminth infections, it is considerably more time-consuming in terms of preparation. ${ }^{7}$ Regarding equipment, FLOTAC is more expensive than Kato-Katz. However, because of the low sensitivity of a single Kato-Katz, examinations of more than just one thick smear, ideally derived from multiple stool samples, are recommended for obtaining reliable results. ${ }^{8}$ Obviously, repeated stool sampling reduces patient compliance, and increases overall costs. Economic evaluations of FLOTAC and its diagnostic potential for detection of eggs of other helminths (e.g. Enterobius vermicularis, Schistosoma mansoni and food-borne 
trematodes) are underway. Finally, the diagnostic accuracy of FLOTAC in anthelminthic drug efficacy trials is the subject of our current investigations in Zanzibar. In view of the results highlighted here, we feel that FLOTAC might become a viable tool for accurate patient management and rigorous monitoring of drug intervention studies and communitybased helminth control programmes.

Authors' contributions: SK, DG, LR, KAM, EKN, GC, DR and JU designed the study; SK, DG, LR, KAM, EKN, JRS, HM, GC and DR collected field and laboratory data; SK, DG, LR, GC and JU analysed the data; SK and JU drafted the manuscript. All authors read, revised and approved the final manuscript. SK and JU are guarantors of the paper.

Acknowledgements: We are grateful to all participating children for their willingness to provide faecal samples for helminth diagnosis. We thank the laboratory teams in Côte d'Ivoire, Zanzibar and Naples, who examined hundreds of Kato-Katz thick smears and FLOTACs under the microscope.

Funding: Our investigations received financial support from the 'Kommission für Reisestipendien des SCNAT' and the Commission for Research Partnerships with Developing Countries. SK is grateful to the Emanuel Burckhardt Foundation and $\mathrm{JU}$ to the Swiss National Science Foundation (project no. PPOOB-102883; PPOOB-119129).

Conflicts of interest: GC is the current patent holder of FLOTAC. All other authors have no conflicts of interest.

Ethical approval: The two studies carried out in Côte d'Ivoire were approved by the institutional research commissions of the Swiss Tropical Institute (Basel, Switzerland) and the Centre Suisse de Recherches Scientifiques (Abidjan, Côte d'Ivoire). The Zanzibar study was approved by WHO (Geneva, Switzerland) and the National Health Service Local Research Ethics Committee of St. Mary's Hospital (London, UK) on behalf of the Natural History Museum/Imperial College London. The studies were cleared by ethical committees and Ministries of Health in Côte d'Ivoire and Zanzibar. Written informed consent was obtained from parents and/or legal guardians of all participating children.

\section{Appendix A. Supplementary data}

Supplementary data associated with this article can be found, in the online version, at doi:10.1016/ j.trstmh.2009.05.012.

\section{References}

1. WHO. Preventive chemotherapy in human helminthiasis: coordinated use of anthelminthic drugs in control interventions: a manual for health professionals and programme managers. Geneva: World Health Organization; 2006.

2. Bergquist R, Johanson MV, Utzinger J. Diagnostic dilemmas in helminthology: what tools to use and when? Trends Parasitol 2009;25:151-6.

3. Cringoli G. FLOTAC, a novel apparatus for a multivalent faecal egg count technique. Parassitologia 2006;48:381-4.

4. Katz N, Chaves A, Pellegrino J. A simple device for quantitative stool thick-smear technique in schistosomiasis mansoni. Rev Inst Med Trop São Paulo 1972;14:397-400.

5. Knopp S, Rinaldi L, Khamis IS, Stothard JR, Rollinson D, Maurelli MP, et al. A single FLOTAC is more sensitive than triplicate Kato-Katz for the diagnosis of low-intensity soiltransmitted helminth infections. Trans $R$ Soc Trop Med Hyg 2009; 103:347-54.

6. Utzinger J, Rinaldi L, Lohourignon LK, Rohner F, Zimmermann $M B$, Tschannen AB, et al. FLOTAC: a new sensitive technique for the diagnosis of hookworm infections in humans. Trans $R$ Soc Trop Med Hyg 2008;102:84-90.

7. Levecke B, De Wilde N, Vandenhoute E, Vercruysse J. Field validity and feasibility of four techniques for the detection of Trichuris in simians: a model for monitoring drug efficacy in public health? PLoS Negl Trop Dis 2009; 3:e366.

8. Knopp S, Mgeni AF, Khamis IS, Steinmann P, Stothard JR, Rollinson $D$, et al. Diagnosis of soil-transmitted helminths in the era of preventive chemotherapy: effect of multiple stool sampling and use of different diagnostic techniques. PLoS Negl Trop Dis 2008;2:e331. 